\title{
IFN-GAMMA-MEDIATED CONTROL OF PISCIRICKETTSIA SALMONIS SURVIVAL IN TROUT MACROPHAGES
}

\author{
Claudio Álvarez ${ }^{1, *}$, Sergio Marshall ${ }^{1, *}$ \& Luis Mercado ${ }^{1, *} \S$ \\ ${ }^{l}$ Grupo de Marcadaores Inmunológicos en Organismos Acuáticos. Laboratorio de Genética e \\ Inmunología Molecular, Facultad de Ciencias, Pontificia Universidad Católica de Valparaíso. \\ Valparaíso, Chile.
}

Piscirickettsia salmonis is a facultative intracellular bacterium responsible for salmon rickettsial syndrome (SRS). This pathogen is able to propagate in salmonid macrophages and can avoid the immune response of the fish host. Existing evidence suggests that $P$. salmonis is able to stop phagosome maturation, thus blocking this cellular antimicrobial mechanism. In higher vertebrates, interferon gamma (IFN $\gamma$ ) is one of the primary cytokines responsible for promoting phagosomelysosome fusion. The objective of this study was to analyze the effect of IFN $\gamma$ on $P$. salmonis survival in salmonid phagocytes. For this, a recombinant salmonid interferon (rIFN $\gamma$ ) and the RTS11 rainbow trout (Oncorhynchus mykiss) cell line were used in the models of cellular infection. The effect of rIFN $\gamma$ in cultures infected with $P$. salmonis was analyzed by detecting bacteria through Western blot and RT-PCR analyses. Moreover, the expression of delayed markers of phagosome maturation was determined. The obtained results indicated that rIFN $\gamma$ decreases the presence of $P$. salmonis in the interior of the cell, while the expression of GTPasas Rab7a and GBP1 were upregulated. This research represents one of the first to present that fish-derived IFN $\gamma$ conserves some of the functional properties described in higher vertebrates, including the ability to regulate phagosome maturation. This interferon could be a therapeutic target for the control of SRS in salmonids.

KEYWORDS: fish Innate immnity, macrophage, intracellular pathogens

*These authors contributed equally to this work.

$\S_{\text {Corresponding author. Tel.: +56 322274860. E-mail address: luis.mercado@pucv.cl }}$ 